\title{
MITOLOGIA E CLIMATOLOGIA: UM ESTUDO DAS DIVINDADES RELACIONADAS À OCORRÊNCIA DE TEMPO SEVERO
}

\author{
CANDIDO, Daniel Henrique \\ CEMADEM E IG/UNICAMP - Universidade de Campinas \\ NUNES, Lucí Hidalgo \\ IG / UNICAMP - Universidade de Campinas
}

\begin{abstract}
Resumo
Este artigo apresenta as principais divindades relacionadas às intempéries atmosféricas, com destaque para aquelas relacionadas a elementos vinculados à ocorrência de tempo severo. Foram coletadas e agrupadas informações sobre diferentes culturas do passado, dando destaque para aquelas que cultuavam divindades sobre as quais esses povos depositavam a confiança de que elas teriam poder sobre as formações de sistemas atmosféricas relacionados a ocorrência de ventos fortes, tempestades e/ou outros fenômenos climático meteorológicos.

Palavras-chave: Tempestades; Clima; Mitologia; Divindades.

MYTHOLOGY AND CLIMATOLOGY: A STUDY OF THE DEITIES RELATED TO THE OCCURRENCE OF SEVERE WEATHER

Abstract

This paper presents the main deities related to weather, in special those linked to the register of severe weather. Information about different cultures of the past was collected and grouped, giving prominence to those that had faith in divinities in which they had strong confidence in their power over the formation of weather systems related to the occurrence of strong winds, storms and / or other meteorological phenomena.

Key-words: Storms; Climate; Mythology; Deities.
\end{abstract}

\section{INTRODUÇÃO}

Ao longo de seu desenvolvimento, as sociedades humanas recorrentemente procuram elucidar dúvidas relacionadas à ocorrência de fenômenos naturais. Diversas culturas antigas apresentam divindades responsáveis pelas manifestações da natureza, o que se relaciona, de acordo com a antropologia cultural ou social, ao desejo do ser humano conhecer sua origem, identidade e ambiente, sendo também um elemento caracterizador dos grupos de acordo com as relações especiais que eles estabelecem com o meio. Assim, a mitologia se constitui em relevante elemento para a compreensão da relação de uma dada sociedade com a natureza, provendo significados dos elementos do meio natural presentes em suas histórias, valores e crenças. E dentre o grande número de figuras divinas existentes nas mitologias de distintas culturas, percebe-se a presença constante de deuses relacionados à atuação das intempéries. Para as mais antigas sociedades as mudanças das condições do tempo estavam ligadas à atuação de seres cujos poderes estariam além de nossa capacidade de compreensão.

Os eventos atmosféricos, especialmente os muito intensos são capazes de estimular ampla gama dos sentidos humanos, sendo detectados de maneiras distintas pelos sistemas visual, auditivo, tátil e até mesmo olfativo. Com isso, a humanidade sempre buscou explicações para essas ocorrências. Esclarecimentos sobre a origem dos fenômenos atmosféricos, que estão entre as mais energéticas manifestações da natureza, são recorrentes nos mitos de distintas civilizações, em muitos casos com grande similaridade. Mesmo as principais religiões incorporaram inúmeros fenômenos atmosféricos em seus sistemas de crenças, em uma tentativa de busca da compreensão das causalidades das intempéries, sendo o dilúvio, provavelmente, o mais recorrente (BRYANT, 1991; VAN MOLLE, 1993; BURROUGHS, 1997). Nunes (1999) lembra que em inúmeras sociedades decisões políticas importantes não eram tomadas sem antes consultar deuses e oráculos, invariavelmente associados às forças da natureza.

As possíveis explicações para os fenômenos climático-meteorológicos variaram de acordo com o grau de desenvolvimento técnico-científico e a cultura de cada sociedade. Assim, o presente estudo objetiva observar como diferentes povos procuravam entender a gênese e causalidades dos fenômenos atmosféricos, tendo sido elaborada para o propósito extensa revisão bibliográfica, que coletou quais eram as principais divindades consideradas pelas populações de culturas 
pretéritas. Como diversos deuses foram repetidamente citados por diferentes autores, utilizaramse as obras dotadas de descrições mais minuciosas.

A Tabela 1 apresenta de forma sistemática as informações levantadas, fundamentadas nas obras de Wainwrigh (1963), Willis (1993), Turner e Coulter (2000), Lurker (2004) e Jordan (2004). Ela mostra distintas divindades associadas aos eventos atmosféricos para inúmeras culturas em diferentes partes do planeta. Como tal tabela objetiva, também, exibir a importância das ocorrências atmosféricas nas diversas civilizações, considerou-se unicamente as divindades relacionadas direta ou indiretamente à ocorrência de alguma intempérie. A discussão de suas relevâncias no sistema de vida dos povos é posteriormente apresentada.

Tabela 1: Divindades relacionadas às condições climáticas e meteorológicas, discriminadas por culturas

\begin{tabular}{|c|c|c|c|c|}
\hline Cultura & Divindade & Atribuição & $\begin{array}{l}\text { Intempéries } \\
\text { relacionadas }\end{array}$ & $\begin{array}{l}\text { Outras informações } \\
\text { relevantes }\end{array}$ \\
\hline Albanesa & Perende & $\begin{array}{c}\text { Deus da } \\
\text { tempestade }\end{array}$ & Tempestades & \\
\hline $\begin{array}{l}\text { Andina } \\
\text { Central }\end{array}$ & Pariacaca & Deus do tempo & Chuvas e trovões & \\
\hline \multirow{3}{*}{ Árabe } & Et Betel & $\begin{array}{c}\text { Deus da } \\
\text { tempestade }\end{array}$ & Tempestades & \\
\hline & Qos & Deus do tempo & Chuvas e arco-íris & \\
\hline & Quzah & $\begin{array}{l}\text { Deus da } \\
\text { montanha e do } \\
\text { tempo }\end{array}$ & Tempestades & \\
\hline Armênia & Barshamin & Deus do tempo & $\begin{array}{l}\text { Ocorrências } \\
\text { meteorológicas } \\
\text { em geral }\end{array}$ & $\begin{array}{c}\text { Provavelmente derivado } \\
\text { da divindade Síria Baal- } \\
\text { Shamin. }\end{array}$ \\
\hline \multirow{3}{*}{ Asteca } & Chalchiuhtlicue & Deusa da água & $\begin{array}{l}\text { Chuvas e } \\
\text { redemoinhos }\end{array}$ & $\begin{array}{c}\text { Teria sido a responsável } \\
\text { por um grande dilúvio que } \\
\text { atingiu a Terra. }\end{array}$ \\
\hline & Tlaloc & Deus da chuva & Chuvas & \\
\hline & Yauhqueme & $\begin{array}{l}\text { Deus da } \\
\text { fertilidade e das } \\
\text { chuvas }\end{array}$ & Chuvas & \\
\hline Bakonga & Lubangala & $\begin{array}{l}\text { Deus do arco- } \\
\text { íris }\end{array}$ & Trovões e arco-íris & \\
\hline ambara & Teliko & $\begin{array}{c}\text { Deus dos } \\
\text { ventos quentes }\end{array}$ & Vento, calor & \\
\hline Bijagó & Oraga & $\begin{array}{l}\text { Deus da chuva } \\
\text { e ventos }\end{array}$ & Chuva, vento & \\
\hline Budista & Hemantadevi & Deusa do & Frio, neve & \\
\hline
\end{tabular}




\begin{tabular}{|c|c|c|c|c|}
\hline & & inverno & & \\
\hline Bunyoro & Munume & Deus do tempo & Secas e cheias & $\begin{array}{c}\text { Era invocado em épocas } \\
\text { de cheias ou secas, para } \\
\text { normalizar a situação. }\end{array}$ \\
\hline \multirow{3}{*}{ Celta } & Áine & Deusa do sol & Início do verão & \\
\hline & Cailleach Bheur & $\begin{array}{l}\text { Deusa do } \\
\text { inverno }\end{array}$ & Neves e Nevascas & \\
\hline & Taranis & Deus do trovão & Trovões & \\
\hline \multirow{3}{*}{ Chinesa } & $\mathrm{Ba}$ & Deusa da seca & Secas & \\
\hline & Chi Sung Tzu & Deus da chuva & Chuva & \\
\hline & Tien Um & Deusa dos raios & Raios & \\
\hline Dinka & Deng & Deus do céu & $\begin{array}{c}\text { Tempestade, raios } \\
\text { e trovões }\end{array}$ & \\
\hline \multirow[b]{2}{*}{ Eslava } & Perun & Deus do trovão & Raios e trovões & \\
\hline & Stribog & $\begin{array}{l}\text { Deus dos } \\
\text { ventos }\end{array}$ & Ventos & \\
\hline Etrusca & Summamus & $\begin{array}{c}\text { Deus da } \\
\text { tempestade }\end{array}$ & Raios e trovões & $\begin{array}{c}\text { Havia um santuário } \\
\text { dedicado a esse deus em } \\
\text { Roma. }\end{array}$ \\
\hline \multirow{2}{*}{ Ewe } & So & Deus do tempo & $\begin{array}{l}\text { Ocorrências } \\
\text { meteorológicas } \\
\text { em geral }\end{array}$ & \\
\hline & Xewioso & Deus do trovão & $\begin{array}{c}\text { Raios, trovões, } \\
\text { tempestades e } \\
\text { chuvas }\end{array}$ & \\
\hline Fenícia & Hadad & Deus do tempo & $\begin{array}{l}\text { Ocorrências } \\
\text { meteorológicas } \\
\text { em geral }\end{array}$ & $\begin{array}{c}\text { Os trovões eram } \\
\text { considerados seus gritos } \\
\text { ecoando através das } \\
\text { nuvens. }\end{array}$ \\
\hline \multirow{3}{*}{ Finlandesa } & Ilmarinen & Deus do céu & $\begin{array}{l}\text { Ocorrências } \\
\text { meteorológicas } \\
\text { em geral }\end{array}$ & $\begin{array}{l}\text { Também era considerado o } \\
\text { responsável pela colocação } \\
\text { das estrelas no céu. }\end{array}$ \\
\hline & Pajonn & Deus do trovão & Trovões & \\
\hline & Ukko & Deus do trovão & Raios e trovões & \\
\hline Fon & Sogbo & $\begin{array}{c}\text { Deus da } \\
\text { tempestade }\end{array}$ & Tempestades & \\
\hline Germânica & Donar & $\begin{array}{l}\text { Deus das } \\
\text { tempestades }\end{array}$ & $\begin{array}{l}\text { Trovões e } \\
\text { tempestades }\end{array}$ & $\begin{array}{c}\text { Derivado da divindade } \\
\text { nórdica Thor }\end{array}$ \\
\hline
\end{tabular}




\begin{tabular}{|c|c|c|c|c|}
\hline \multirow[b]{4}{*}{ Grega } & Aeolos & $\begin{array}{c}\text { Deus das } \\
\text { tempestades e } \\
\text { ventos }\end{array}$ & $\begin{array}{l}\text { Tempestades e } \\
\text { ventos severos }\end{array}$ & $\begin{array}{l}\text { Era um dos filhos de } \\
\text { Poseidon. }\end{array}$ \\
\hline & Okeanos & $\begin{array}{l}\text { Deus dos } \\
\text { oceanos }\end{array}$ & $\begin{array}{c}\text { Ondas, marés e } \\
\text { tormentas }\end{array}$ & \\
\hline & Zibelthiurdos & $\begin{array}{c}\text { Deus da } \\
\text { tempestade }\end{array}$ & Raios e trovões & \\
\hline & Eos & Deusa do céu & Ventos e orvalho & $\begin{array}{l}\text { Teve seis filhos cada um } \\
\text { dos quais representava um } \\
\text { determinado vento. Ela } \\
\text { também foi mãe de } \\
\text { Mennon, que morreu em } \\
\text { Tróia, e por isso chora } \\
\text { todas as noites. Suas } \\
\text { lágrimas formariam o } \\
\text { orvalho que se assenta } \\
\text { sobre a relva durante as } \\
\text { manhãs. }\end{array}$ \\
\hline \multirow{6}{*}{ Hindu } & Agnikumara & Divindade & Chuvas e trovões & \\
\hline & Hi'lina & Deus tribal & Nuvens e trovões & $\begin{array}{c}\text { Era representado por uma } \\
\text { ave gigante, cujo bater de } \\
\text { asas gerava o som dos } \\
\text { trovões. O brilho de seu } \\
\text { olhar formava os raios e } \\
\text { as nuvens saiam de sua } \\
\text { cloaca. }\end{array}$ \\
\hline & Indra & Deus do tempo & $\begin{array}{l}\text { Ocorrências } \\
\text { meteorológicas } \\
\text { em geral }\end{array}$ & \\
\hline & Maruts & $\begin{array}{l}\text { Deuses das } \\
\text { tempestades }\end{array}$ & Tempestades & \\
\hline & Parjanya & Deus da chuva & Chuvas & \\
\hline & Pavana & Deus do vento & Ventos & \\
\hline \multirow{3}{*}{ Huichol } & $\begin{array}{l}\text { Tamats Palike } \\
\text { Tamoyeke }\end{array}$ & $\begin{array}{c}\text { Deus do ar e do } \\
\text { vento }\end{array}$ & Ventos & \\
\hline & $\begin{array}{l}\text { Tate Hautse } \\
\text { Kupuri }\end{array}$ & $\begin{array}{c}\text { Deusa das } \\
\text { águas e da } \\
\text { chuva }\end{array}$ & Chuva & $\begin{array}{l}\text { Responsável pela chuva } \\
\text { vinda do ocidente. }\end{array}$ \\
\hline & Tate Naaliwahi & $\begin{array}{l}\text { Deusa das } \\
\text { águas e da } \\
\text { chuva }\end{array}$ & Chuva & $\begin{array}{l}\text { Responsável pela chuva } \\
\text { vinda do oriente. }\end{array}$ \\
\hline
\end{tabular}


Revista Brasileira de Climatologia

ISSN: 1980-055x (Impressa) 2237-8642 (Eletrônica)

\begin{tabular}{|c|c|c|c|c|}
\hline \multirow[b]{2}{*}{ Inca } & Apocatequil & Deus dos raios & Raios e trovões & \\
\hline & Waconera & $\begin{array}{l}\text { Entidade } \\
\text { maligna }\end{array}$ & Secas & \\
\hline Inca & Ilyapa & Deus do tempo & $\begin{array}{c}\text { Chuvas, raios e } \\
\text { trovões }\end{array}$ & \\
\hline Inuit & Ignerssuak & Deus dos mares & Tormentas & \\
\hline \multirow{4}{*}{ Kaffir } & Bagisht & $\begin{array}{l}\text { Deus das } \\
\text { águas, } \\
\text { inundações e } \\
\text { prosperidade }\end{array}$ & $\begin{array}{l}\text { Chuvas e } \\
\text { inundações }\end{array}$ & $\begin{array}{l}\text { Como trazia as chuvas } \\
\text { após a estação seca, essa } \\
\text { cultura afegã considerava } \\
\text { esse deus, como um dos } \\
\text { responsáveis pela } \\
\text { prosperidade. }\end{array}$ \\
\hline & Inder & Deus do tempo & $\begin{array}{l}\text { Ocorrências } \\
\text { meteorológicas } \\
\text { em geral }\end{array}$ & \\
\hline & Nong & $\begin{array}{l}\text { Deus do inverno } \\
\text { e do tempo frio }\end{array}$ & $\begin{array}{c}\text { Frio, geadas e } \\
\text { neve }\end{array}$ & \\
\hline & Sudrem & Deus do tempo & Chuvas & \\
\hline \multirow[t]{2}{*}{ Letã } & Bangputys & Deus do Mar & $\begin{array}{l}\text { Ondas e } \\
\text { tormentas }\end{array}$ & \\
\hline & Perkons & Deus do trovão & Raios e trovões & \\
\hline Lovedu & Mujaji & Deusa da chuva & $\begin{array}{c}\text { Chuvas e } \\
\text { tempestades }\end{array}$ & $\begin{array}{c}\text { Em períodos de } \\
\text { tempestades costumava- } \\
\text { se sacrificar gado e até } \\
\text { mesmo jovens garotas } \\
\text { para acalmar a ira dessa } \\
\text { deusa. }\end{array}$ \\
\hline \multirow{5}{*}{ Maia } & Ah Kin & Deus do sol & Secas & \\
\hline & Ah Patnar Uinicob & $\begin{array}{l}\text { Auxiliares dos } \\
\text { deuses das } \\
\text { águas }\end{array}$ & $\begin{array}{l}\text { Chuvas (fim da } \\
\text { estação seca) }\end{array}$ & $\begin{array}{l}\text { Consistiam em quatro } \\
\text { divindades que } \\
\text { derramavam jarros de } \\
\text { água sobre a Terra. }\end{array}$ \\
\hline & Ah Peku & Deus do trovão & Trovões & \\
\hline & Chaac & Deus da chuva & $\begin{array}{c}\text { Chuvas, raios e } \\
\text { trovões }\end{array}$ & \\
\hline & Chaob & $\begin{array}{l}\text { Deus dos } \\
\text { ventos }\end{array}$ & Ventos & $\begin{array}{c}\text { Seu sopro era relacionado } \\
\text { como causa dos ventos. A } \\
\text { lenda diz que ele era } \\
\text { capaz de soprar com força } \\
\text { suficiente para derrubar os } \\
\text { macacos das árvores. }\end{array}$ \\
\hline
\end{tabular}




\begin{tabular}{|c|c|c|c|c|}
\hline & Chiccan & Deus da chuva & $\begin{array}{l}\text { Formação das } \\
\text { nuvens e chuva }\end{array}$ & $\begin{array}{l}\text { Possuía a forma de um } \\
\text { réptil gigante e era } \\
\text { cercado por cobras. }\end{array}$ \\
\hline & Menzabac & Deus do tempo & $\begin{array}{l}\text { Nuvens escuras e } \\
\text { chuva }\end{array}$ & $\begin{array}{c}\text { Ele espalha tintura preta } \\
\text { nas nuvens, o que as } \\
\text { deixaria escuras, causando } \\
\text { as chuvas. }\end{array}$ \\
\hline & Tzultacah & Deus do trovão & Trovões e chuvas & \\
\hline \multirow{4}{*}{$\begin{array}{l}\text { Mesopo- } \\
\text { tâmia }\end{array}$} & An & Deusa do céu & Chuvas & $\begin{array}{c}\text { Considerada a criadora do } \\
\text { universo. }\end{array}$ \\
\hline & $\mathrm{Im}$ & $\begin{array}{c}\text { Deus da } \\
\text { tempestade }\end{array}$ & Tempestades & \\
\hline & Ishkur & $\begin{array}{c}\text { Deus das } \\
\text { tempestades }\end{array}$ & $\begin{array}{l}\text { Tempestades, } \\
\text { raios e trovões }\end{array}$ & \\
\hline & Wer & $\begin{array}{c}\text { Deus da } \\
\text { tempestade }\end{array}$ & Tempestades & \\
\hline \multirow{5}{*}{ Navaho } & Dsahadoldza & $\begin{array}{c}\text { Deus da terra e } \\
\text { da água }\end{array}$ & Chuvas & \\
\hline & Hastseyalti & $\begin{array}{l}\text { Chefe dos } \\
\text { deuses }\end{array}$ & Chuva & \\
\hline & Klehanoai & Deus da Lua & Raios & \\
\hline & Tienoltsodi & $\begin{array}{l}\text { Deus da água } \\
\text { doce }\end{array}$ & Chuvas & $\begin{array}{c}\text { Responsável pela } \\
\text { distribuição da água doce } \\
\text { que cai sobre a Terra. }\end{array}$ \\
\hline & Tonenili & Deus da chuva & $\begin{array}{c}\text { Chuvas e } \\
\text { tempestades }\end{array}$ & \\
\hline \multirow{4}{*}{ Nórdica } & Aegir & Deus do mar & $\begin{array}{l}\text { Ondas e } \\
\text { tormentas } \\
\text { oceânicas }\end{array}$ & \\
\hline & Heimdall & $\begin{array}{l}\text { Guardião dos } \\
\text { deuses }\end{array}$ & Arco-íris & \\
\hline & $\mathrm{Hel}$ & $\begin{array}{c}\text { Deusa dos } \\
\text { subterrâneos }\end{array}$ & $\begin{array}{l}\text { Elevação do nível } \\
\text { do mar }\end{array}$ & \\
\hline & Horagalles & Deus do tempo & $\begin{array}{l}\text { Ocorrências } \\
\text { meteorológicas } \\
\text { em geral }\end{array}$ & $\begin{array}{l}\text { Versão sueca do deus } \\
\text { Thor, contudo, carregando } \\
\text { dois martelos. }\end{array}$ \\
\hline
\end{tabular}




\begin{tabular}{|c|c|c|c|c|}
\hline & Snær & $\begin{array}{l}\text { Divindade da } \\
\text { Neve }\end{array}$ & Gelo e neve & \\
\hline & Thor & $\begin{array}{c}\text { Deus da guerra, } \\
\text { do céu e das } \\
\text { tempestades }\end{array}$ & $\begin{array}{l}\text { Tempestades, } \\
\text { raios e trovões }\end{array}$ & $\begin{array}{l}\text { Um dos mais importantes } \\
\text { deuses da mitologia } \\
\text { nórdica. Ele cruza o céu } \\
\text { com uma carruagem } \\
\text { puxada por duas cabras, } \\
\text { cujas rodas causam o som } \\
\text { dos trovões. Ao bater com } \\
\text { seu martelo em uma } \\
\text { rocha, produzia faíscas } \\
\text { que atingiam a terra na } \\
\text { forma de raios. }\end{array}$ \\
\hline Nupe & Soko & Deus do céu & $\begin{array}{c}\text { Nuvens escuras, } \\
\text { chuva }\end{array}$ & \\
\hline Persa & Vata & Deus do vento & Vento & \\
\hline Pokot & Ilat & Deus da chuva & Chuva & \\
\hline Polinésia & Tawhirimatea & Deus do vento & Vento & \\
\hline \multirow{5}{*}{ Romana } & Aeolus & $\begin{array}{l}\text { Deus das } \\
\text { tempestades }\end{array}$ & $\begin{array}{l}\text { Tempestades e } \\
\text { ventos severos }\end{array}$ & $\begin{array}{c}\text { Derivado do deus grego } \\
\text { Aeolos. }\end{array}$ \\
\hline & Aquilo & Deus do tempo & $\begin{array}{l}\text { Ocorrências } \\
\text { meteorológicas } \\
\text { em geral }\end{array}$ & $\begin{array}{c}\text { Também considerado } \\
\text { como deus do vento de } \\
\text { oeste. }\end{array}$ \\
\hline & Corus & Deus do vento & Ventos & $\begin{array}{c}\text { Responsável pelo vento } \\
\text { noroeste }\end{array}$ \\
\hline & Juno & $\begin{array}{l}\text { Rainha dos } \\
\text { deuses }\end{array}$ & Tempestades & $\begin{array}{l}\text { Na verdade Juno não era } \\
\text { capaz de provocar } \\
\text { tempestades sozinha, mas } \\
\text { tinha o poder de convocar } \\
\text { os deuses competentes } \\
\text { para tal, quando julgasse } \\
\text { necessário }\end{array}$ \\
\hline & Júpiter & Líder do & Raios e trovões & \\
\hline
\end{tabular}




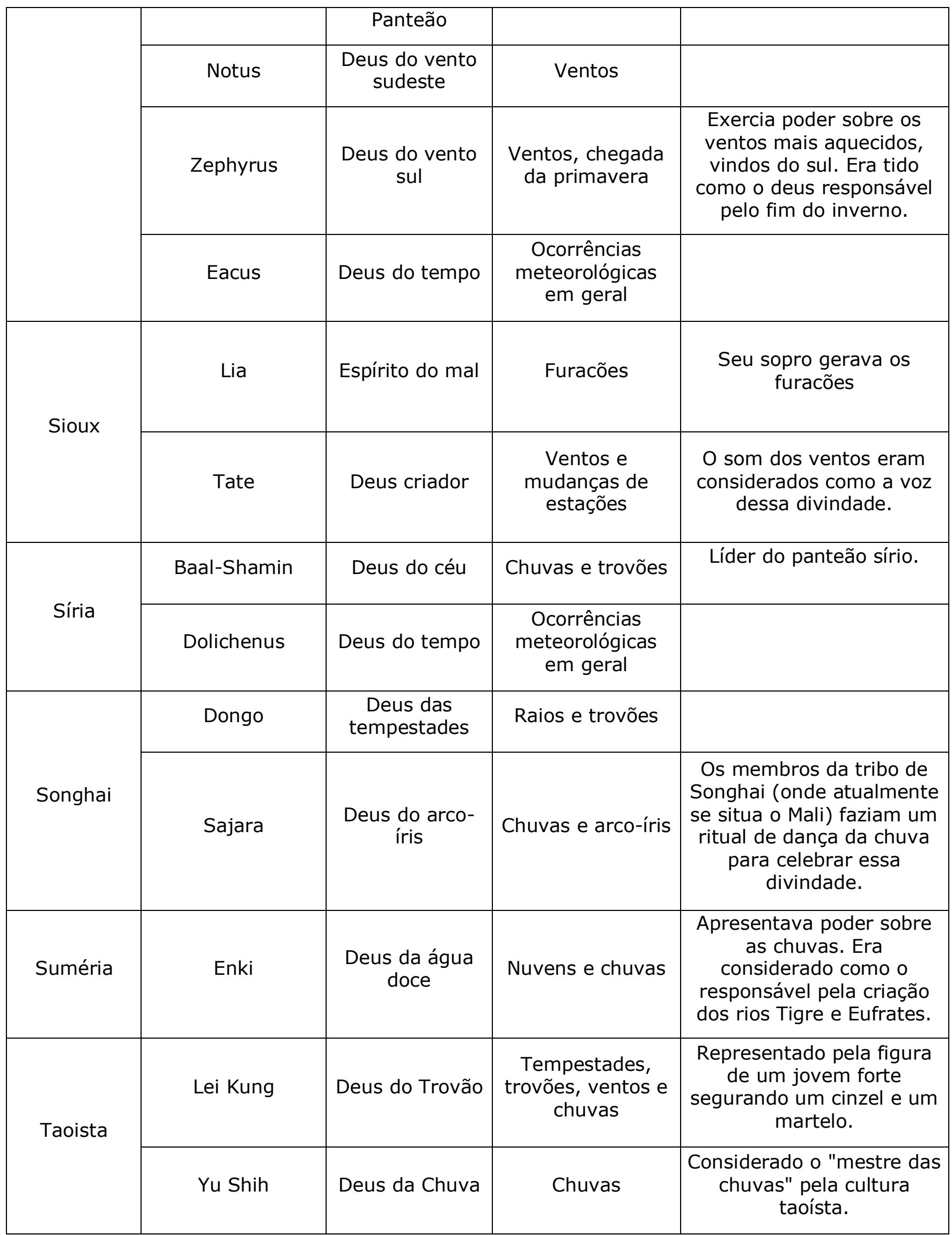




\begin{tabular}{|c|c|c|c|c|}
\hline Totonac & Tajin & $\begin{array}{l}\text { Deus das } \\
\text { chuvas }\end{array}$ & $\begin{array}{c}\text { Nuvens, chuvas e } \\
\text { trovões }\end{array}$ & \\
\hline \multirow{3}{*}{$\begin{array}{l}\text { Tupi- } \\
\text { Guarani }\end{array}$} & Iara & $\begin{array}{l}\text { Deusa das } \\
\text { águas }\end{array}$ & Neblina e cheias & \\
\hline & Tupã & $\begin{array}{l}\text { Divindade das } \\
\text { chuvas }\end{array}$ & Raios e trovões & $\begin{array}{l}\text { Tupã não era exatamente } \\
\text { um deus, mas sim uma } \\
\text { manifestação de } \\
\text { Nhanderuvuçu na forma } \\
\text { de um trovão. }\end{array}$ \\
\hline & Nhanderuvuçu & Deus supremo & $\begin{array}{l}\text { Ocorrências } \\
\text { meteorológicas } \\
\text { em geral }\end{array}$ & \\
\hline Wagadou & $\begin{array}{l}\text { Ataa Naa } \\
\text { Nyongmo }\end{array}$ & O criador & Sol e chuva & \\
\hline \multirow{10}{*}{ toísta } & $\begin{array}{l}\text { Aji-Shiki-Taka- } \\
\text { Hiko-Ne }\end{array}$ & Deus da chuva & Chuvas & \\
\hline & Fujin & $\begin{array}{l}\text { Deus dos } \\
\text { ventos }\end{array}$ & Ventos & $\begin{array}{l}\text { Acredita-se que ele } \\
\text { carregava um saco sobre } \\
\text { os ombros, dentro do qual } \\
\text { estavam os quatro ventos. }\end{array}$ \\
\hline & Haya-Ji & $\begin{array}{l}\text { Deus dos } \\
\text { ventos }\end{array}$ & $\begin{array}{c}\text { Ventos, } \\
\text { redemoinhos e } \\
\text { tufões }\end{array}$ & \\
\hline & $\begin{array}{l}\text { Iku-Ikasuchi-No- } \\
\text { Kami }\end{array}$ & Deus do trovão & Trovões & $\begin{array}{c}\text { Era um dos deuses mais } \\
\text { significativos para essa } \\
\text { cultura. }\end{array}$ \\
\hline & Inazuma & Deus dos raios & Raios & \\
\hline & Izanami-No-Kami & O criador & Trovões & \\
\hline & $\begin{array}{l}\text { Kamo-Wake- } \\
\text { Ikazuchi }\end{array}$ & Deus da chuva & Chuvas & \\
\hline & Karai-Shin & Deus dos raios & Raios & \\
\hline & $\begin{array}{l}\text { Kura-Okami-No- } \\
\text { Kami }\end{array}$ & Deus da chuva & Chuva, Neve & \\
\hline & Raijin & Deus do tempo & $\begin{array}{l}\text { Raios, trovões, } \\
\text { tempestades e } \\
\text { chuvas }\end{array}$ & $\begin{array}{l}\text { Nome genérico dado a } \\
\text { vários deuses do tempo. }\end{array}$ \\
\hline
\end{tabular}




\begin{tabular}{|c|c|c|c|c|}
\hline & Ryujin & Deus do tempo & $\begin{array}{l}\text { Raios, trovões, } \\
\text { tempestades e } \\
\text { chuvas }\end{array}$ & \\
\hline & Shina-Tsu-Niko & $\begin{array}{l}\text { Deus dos } \\
\text { ventos }\end{array}$ & $\begin{array}{l}\text { Ventos, dispersão } \\
\text { da neblina matinal }\end{array}$ & $\begin{array}{c}\text { A essa divindade é } \\
\text { atribuída uma façanha } \\
\text { ocorrida no século XIII, } \\
\text { quando o exercito de } \\
\text { Gengis Khan foi impedido } \\
\text { de avançar devido aos } \\
\text { fortes ventos que } \\
\text { sopravam. }\end{array}$ \\
\hline & $\begin{array}{c}\text { Taka-Okami-No- } \\
\text { Kami }\end{array}$ & $\begin{array}{l}\text { Deus das } \\
\text { chuvas }\end{array}$ & Chuvas & $\begin{array}{c}\text { Era considerado o } \\
\text { causador das chuvas nas } \\
\text { montanhas. }\end{array}$ \\
\hline & $\begin{array}{c}\text { Take-Mika- } \\
\text { Dzuchi-No-Kami }\end{array}$ & $\begin{array}{c}\text { Deus das } \\
\text { tempestades }\end{array}$ & $\begin{array}{l}\text { Tempestades, } \\
\text { trovões e chuvas }\end{array}$ & \\
\hline \multirow{2}{*}{ Yakut } & Yina'mna'ut & $\begin{array}{l}\text { Espirito do } \\
\text { nevoeiro e da } \\
\text { neblina }\end{array}$ & $\begin{array}{c}\text { Frio, nevoeiro e } \\
\text { neblina }\end{array}$ & $\begin{array}{l}\text { Seu nome, na linguagem } \\
\text { local, significa Homem da } \\
\text { Neblina.Apresenta uma } \\
\text { versão feminina chamada } \\
\text { de Yina'mtian. }\end{array}$ \\
\hline & Yina'mtian & $\begin{array}{l}\text { Espirito do } \\
\text { nevoeiro e da } \\
\text { neblina }\end{array}$ & $\begin{array}{c}\text { Frio, nevoeiro e } \\
\text { neblina }\end{array}$ & $\begin{array}{c}\text { Seu nome significa Mulher } \\
\text { da Neblina. Apresenta uma } \\
\text { versão Masculina chamada } \\
\text { de Yina'mna'u }\end{array}$ \\
\hline \multirow[t]{2}{*}{ Yoruba } & Sango & Deus do trovão & Trovões & $\begin{array}{l}\text { Representado por um } \\
\text { carneiro, cujo berro era o } \\
\text { som dos trovões. }\end{array}$ \\
\hline & Shango & $\begin{array}{l}\text { Deus da } \\
\text { tempestade }\end{array}$ & $\begin{array}{l}\text { Tempestades, } \\
\text { raios e trovões }\end{array}$ & \\
\hline Zapoteca & Cocijo & Deus da chuva & Chuva & \\
\hline Zulu & Inkanyamba & $\begin{array}{l}\text { Deus das } \\
\text { tempestades }\end{array}$ & $\begin{array}{l}\text { Tempestades e } \\
\text { tornados }\end{array}$ & $\begin{array}{l}\text { Os tornados eram } \\
\text { considerados pelo povo } \\
\text { Zulu como grandes } \\
\text { serpentes que desciam dos } \\
\text { céus para a Terra, sob } \\
\text { ordem dessa divindade. }\end{array}$ \\
\hline
\end{tabular}

\section{RESULTADOS E DISCUSSÃO}

Os egípcios atribuíam ao deus Seth o título de divindade dos ventos, tempestades e raios (WAINWRIGH, 1963; LURKER, 2004). Esse deus era, por vezes, definido como "o senhor dos céus 
do norte" e apresentava total controle sobre os eventos atmosféricos (JORDAN, 2004). Essa referência ao norte é interessante, uma vez que é dessa direção que provêm os principais sistemas frontais que atingem as terras egípcias em certos períodos do ano, o que mostra íntima ligação entre a mitologia e os elementos climático-meteorológicos observados empiricamente pela população da época. Salienta-se, também, que diversos estudos indicam que o clima egípcio era mais chuvoso no período das dinastias dos faraós do que atualmente (HAYES, 1964; BRYANT, 1997; TALBOT, 1980, NICOL, 2001), o que deixa claro uma intencionalidade na atribuição desse deus como detentor de poderes sobre as tormentas.

Já a mitologia grega atribuía o poder de controle das intempéries a Zeus, o supremo líder do panteão. Segundo a crença, esse deus era o responsável pela formação de todos os fenômenos atmosféricos, tendo a capacidade de agrupar e dissipar as nuvens, comandar as tempestades e criar relâmpagos e trovões, os quais lançava à Terra conforme sua vontade. Era o responsável pela distribuição das chuvas, a qual derramava ao solo com a função de fecundar a terra (LURKER, 2004). A escolha de Zeus - o mais importante deus do Olimpo - para comandar as intempéries atesta que os gregos, assim como os egípcios tinham enorme fascínio pelas tempestades. O poder de agrupar e dissipar as nuvens a Zeus mostra que esse povo observava com admiração a rápida velocidade com que as condições de tempo podem se alterar. Mesmo com um conhecimento científico limitado, esse antigo povo percebeu que a dinâmica envolvida na formação das chuvas era bastante complexa, a ponto de ser atribuída somente a Zeus, o deus mais poderoso.

Além disso, os gregos nutriam a crença de que diversas divindades relacionadas aos ventos se reuniam em um local chamado Anemoi ${ }^{1}$ (JORDAN, 2004). Dentre as entidades divinas ali presentes destacavam-se: Boreas, o deus responsável pelos ventos frios do norte, responsável por trazer o domínio do inverno, de onde deriva o termo boreal, sinônimo de norte; Notus, que enviava os ventos quentes e úmidos do sul, comumente presentes no verão, de modo que, este deus era relacionado à ocorrência de tempestades severas; Eurus que representava o indesejado vento leste, que trazia chuvas acompanhadas de tempo abafado e Zephyrus, que trazia o vento oeste que começava a soprar no fim do inverno, sendo assim considerado como um mensageiro da primavera e celebrado por encerrar o período mais frio do ano.

Os povos nórdicos também apresentavam rica mitologia, na qual conferiam a Thor o título de defensor do panteão. Essa divindade, também chamada de Donner ou Donar por alguns povos da região, era amplamente cultuada pelos vikings e considerada como deus do trovão, dos raios, do céu e das chuvas. Thor era considerado o Príncipe dos Deuses, uma vez que presidia e administrava o céu, o ar, o vento, as chuvas e as tempestades (LURKER, 2004). Também era considerado o responsável por combater doenças e a fome na Terra, estando associado aos atos de resistência sobre-humana. Na maioria das línguas germânicas a palavra que designa a quintafeira tem sua etimologia ligada à $\operatorname{Thor}^{2}$ uma vez que esse era o dia consagrado a esse deus, o que denota sua importância (JORDAN, 2004).

Outro deus nórdico responsabilizado pela ocorrência de tempestades era Odin, pai de Thor. Segundo a lenda, ele era capaz de organizar tormentas por meio do movimento de suas mãos.

Assim, também a mitologia nórdica fornece inúmeros exemplos que demonstram a importância que os povos da antiguidade davam às formações tempestuosas, já que Odin era o líder do panteão e Thor, o mais forte dentre todos os deuses presentes nessa cultura. Isso evidencia que

${ }^{1}$ Foi desse termo que originou a palavra anemômetro - nome dado ao instrumento utilizado para medição das velocidades do vento.

2 Como exemplo é conveniente destacar os termos Donnerstag, em alemão; Torsdag, em norueguês, dinamarquês e sueco; Donderdag, em holandês e africâner; Torstai, em finlandês e Thursday, em inglês. 
ainda que os povos nórdicos não tivessem conhecimento dos mecanismos envolvidos na origem de tais intempéries, tinham ciência de que intensos poderes estavam envolvidos em sua formação.

$\mathrm{Na}$ América pré-colombiana tal aspecto também esteve presente. A cultura Maia idolatrava Gucumatz como sendo o deus das tempestades e Huracan, um dos principais deuses desse povo, está ligado à presença de chuvas e fortes, ventos e associado à ocorrência de um dilúvio de proporção planetária (JORDAN, 2004). Como nos exemplos anteriores, um dos principais deuses da cultura em questão é colocado como o responsável por aspectos ligados à ocorrência de tempo severo. Destaca-se que a palavra espanhola para furacão (huracán), tem sua origem nessa mitologia, de onde também deriva o termo em português (furacão), em inglês (hurricane), em francês (ouragan), em italiano (uragano), em alemão (hurrikan) e em diversos outros idiomas.

O povo Navaho, que originalmente vivia em terras que hoje compõem os Estados Unidos, também atribuía aos deuses a ocorrência das intempéries, tendo inclusive desenvolvido cerimoniais para atrair ou afastar as chuvas, fazendo uso de oferendas a determinadas divindades como Tienoltsodi (JORDAN, 2004), que seria o responsável pela distribuição da água doce no planeta, controlando assim a quantidade de chuva precipitada em diferentes pontos da Terra.

As civilizações antigas da América do Sul faziam sacrifícios e rezavam para seus deuses em busca de proteção em relação aos desastres naturais. De acordo com a mitologia Asteca o universo não seria eterno e passaria por cinco ciclos de nascimento e destruição, sendo que o mundo já teria sido destruído quatro vezes: a segunda por furacão, a terceira por fogo e a quarta, por inundação (WILLIS, 1993). Já os Incas atribuíam a Waconera - um deus maligno, devorador de crianças - as secas que assolavam de tempos em tempos as costas peruanas.

Tupis e Guaranis que habitavam boa parte do território brasileiro e de outros países sul americanos, como o Paraguai, também tinham suas crenças em determinadas divindades relacionadas às intempéries (LURKER, 2004): Nhanderuvuçu, $=0$ deus supremo, tinha o poder de se manifestar como Tupã, um mensageiro que surgia na forma de um trovão. Esse deus também era o responsável pelas ocorrências meteorológicas em geral. Havia também a deusa Iara, também conhecida como a mãe das águas, que está relacionada à formação de névoa e neblinas e ao poder do fluxo de água dos cursos d'água. Acreditava-se que quando um índio desaparecia nas correntezas de um rio teria sido levado por tal entidade.

\section{CONCLUSÕES}

O panorama exposto neste trabalho mostra que desde os primórdios da civilização houve preocupação em explicar de onde eram originadas as energéticas manifestações das intempéries. Os povos que habitavam áreas onde prevalecem situações atmosféricas mais instáveis apresentavam maior quantidade de divindades relacionadas à ocorrência de tempo severo, tais como ventos e chuvas fortes, raios, trovões e tempestades. Não obstante, há de se considerar que as civilizações da África e Eurásia são mais antigas que a americana, o que explica a menor quantidade de divindades relacionadas aos elementos do clima presentes no Novo Mundo.

Povos que habitavam áreas assoladas por prolongados períodos de estiagem, como os Bunyoro (Uganda), Maias (Península de Yucatan), Incas (atual Peru) e Chineses (China Central), apresentavam recorrentes deuses relacionados às secas. Por sua vez, sociedades politeístas que habitavam locais cujos climas proporcionam ocorrência de inverno rigoroso, como os Kaffir (montanhas do Afeganistão), Budistas (Tibet), Xintoísta (Japão), Yakut (Sibéria), Nórdicos (norte 
da Europa) e Celtas (ilhas britânicas) citavam deuses relacionados à ocorrência de frio, formação de geadas e queda de neve.

Seguindo essa tendência, observa-se a existência de divindades relacionadas à ocorrência de tempo severo nas populações assentadas nas áreas de climas mais transicionais do planeta naturalmente mais suscetíveis a estas ocorrências - ou ainda nas crenças de povos que habitavam locais sob influência de sistemas que provocam fortes chuvas sazonais. O mesmo aspecto é percebido nos agrupamentos humanos presentes nas áreas afetadas pelas formações de tempestades tropicais e extratropicais, o que explicaria a presença de ícones similarmente relacionados ao clima em culturas tão distintas, como a Xintoísta (Japão), Yoruba (Nigéria), Lovedu (África do Sul), Hindu (Índia), Grega (Império Grego), Romana (Império Romano), Taoísta (China) Tupi e Guarani (países sul americanos), Sioux (EUA), Navaho (EUA), Maia (México), Huichol (México) e Asteca (América Central), entre outras.

Embora deva ser visto com ressalvas em função da possível ocorrência de mudanças climáticas ao longo do tempo histórico, o mapa exibido na Figura 1 mostra que a localização geográfica de tais populações coincide com as áreas de maior incidência de descargas atmosféricas, o que evidencia a frequente presença de tempestades justamente onde estavam essas civilizações

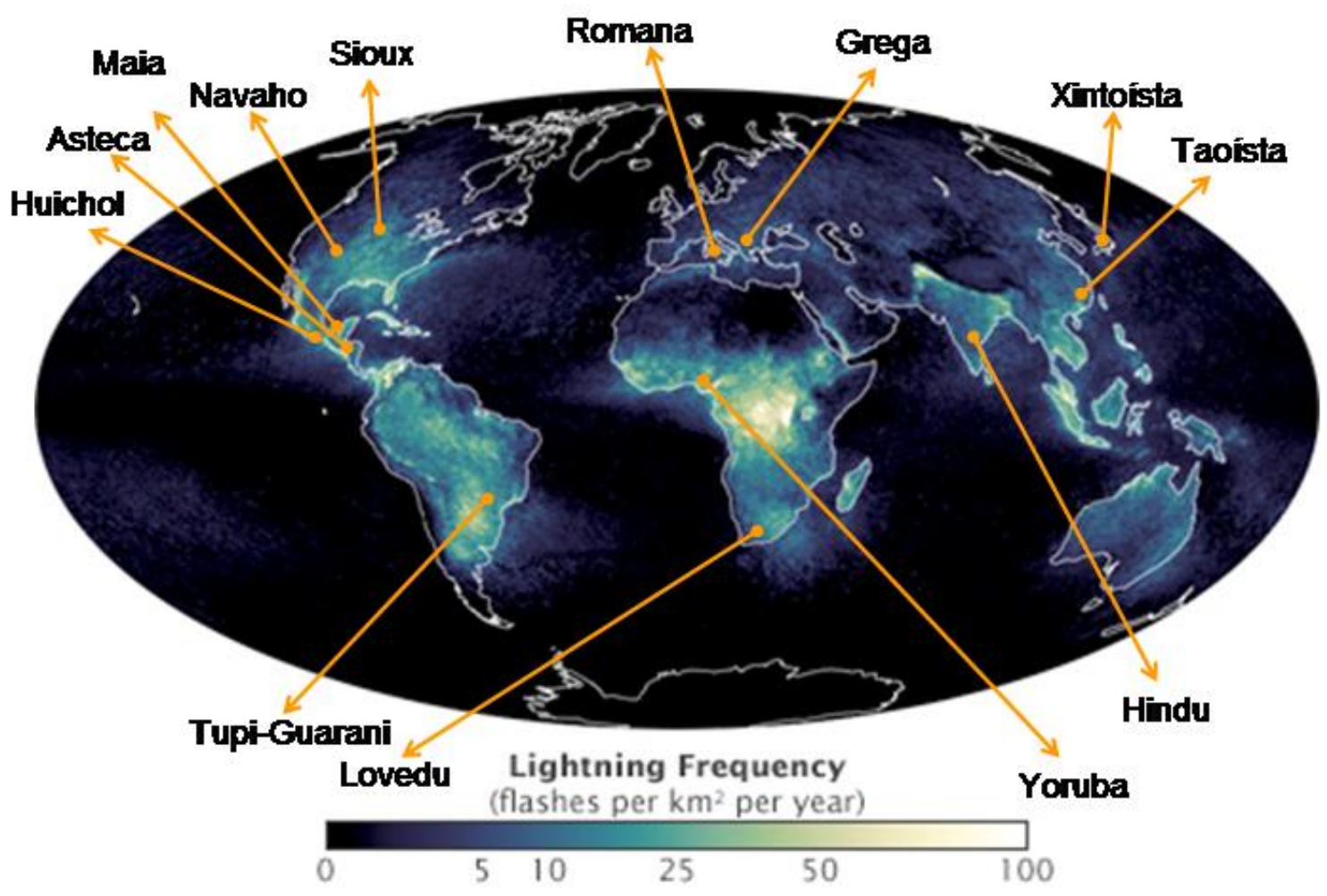

Figura 1

Concentração média anual da ocorrência de descargas elétricas no Planeta e localização de algumas culturas que apresentam divindades relacionadas à ocorrência de raios (adaptado de http://earthobservatory.nasa.gov) 
As informações presentes na Tabela 1 permitem, também, constatar que desde tempos imemoriais a sociedade humana vem observando eventos atmosféricos extremos, dentre os quais é possível destacar a ocorrência de tempestades, tornados e furacões. A existência de deuses relacionados às intempéries em culturas pré-colombianas instaladas em setores que, posteriormente, se tornariam parte do território brasileiro, indica que a ocorrência de eventos de tempestades não eram incomuns neste setor.

\section{REFERÊNCIAS}

BRYANT, E.A. Climate process and change. Cambridge: Cambridge University Press. 1997. 209p.

BURROUGHS, W.J. Does the weather really matters? the social implications of climate change. Cambridge: Cambridge University Press. 1997, 230p.

EARTH OBSERVATORY. Disponível em: <http://earthobservatory.nasa.gov>

HAYES, W.C. Most Ancient Egypt. Journal of Near Eastern Studies, v. 23, n.2, p, 145-162, 1964

JORDAN, M. Dictionary of Gods and Godesses. New York: Facts on file Inc. 2004

LURKER, M. The Routledge Dictionary of Gods and Goddesses, Devils and Demons. London: Routledge. 2004

NICOL, K. Radiocarbon Chronologies for Prehiostric Human Occupation and Hydroclimatic Change in Egypt and Northern Sudan Geoarchaeology v.16, n.1, p, 47-64, 2001. Disponível em:

<http://www.geog.ox.ac.uk/ knicoll/ww/geoarch_nicoll_c14_esahara.pdf>

NUNES, L.H. A influência do clima na história. Rev. Geopantanal v.5, p, 15-23, 1999

SANTY, B.R.V.H. As representações sociais das mudanças do clima e suas implicações no processo de territorialização: os Bijagó da Ilha de Formosa, Guiné-Bissau. Dissertação Mestrado - Centro de Educação e Ciências Humanas, Universidade Federal de São Carlos, 2012 (inédito).

TALBOT, M.R. Environmental Responses to climatic change in the Western African Sahel over the past 20,000 years IN: WILliANS, A.J; HUGUES, F. The Sahara and the Nile. Roterdam: Balkema, 1980

TURneR, P.; COULTER, C.R. Dictionary of Ancient Deities. New York: University Press, 2000

VAN MOLLE, M. Natural hazards. In: NATH, B., HENS, L., COMPTAN, P., DEVUYST, D. (Eds.) Environmental Management v.1-The compartmental approach. Brussels: VUB University Press, p, 305-340, 1993

WAINWRIGHT, G.A. The Origin of Storm Gods in Egypt. Journal of Egyptian Archaeology, v. 49, p, 13-20, 1963

WILLIS, R.G. World Mythology. New York: H. Holt. 2003 